\title{
A seletividade espacial das multinacionais brasileiras nos governos de Fernando Henrique Cardoso e Luiz Inácio Lula da Silva.
}

The space selectivity of brazilian multinationals in the governments of Frnando Henrique Cardoso and Luiz Iinácio Lula da Silva La selectividad espacial de las multinacionales brasileñas en los gobiernos de Fernando Henrique Cardoso y Luiz Inacio Lula da Silva La sélectivité spatiale des multinationales brésiliennes dans les gouvernements de Fernando Henrique Cardoso et Luiz Inácio Lula da Silva

\section{Luís Alberto Miranda Goveia e Elzira Lucia de Oliveira}

\section{OpenEdition}

Journals

\section{Edição electrónica}

URL: http://journals.openedition.org/espacoeconomia/3061

DOI: 10.4000/espacoeconomia.3061

ISSN: 2317-7837

\section{Editora}

Núcleo de Pesquisa Espaço \& Economia

Refêrencia eletrónica

Luís Alberto Miranda Goveia e Elzira Lucia de Oliveira, "A seletividade espacial das multinacionais brasileiras nos governos de Fernando Henrique Cardoso e Luiz Inácio Lula da Silva. », Espaço e Economia [Online], 11 | 2017, posto online no dia , consultado o 04 junho 2020. URL : http:// journals.openedition.org/espacoeconomia/3061; DOI : https://doi.org/10.4000/espacoeconomia. 3061

Este documento foi criado de forma automática no dia 4 junho 2020.

(C) NUPEE 


\section{A seletividade espacial das multinacionais brasileiras nos governos de Fernando Henrique Cardoso e Luiz Inácio Lula da Silva.}

The space selectivity of brazilian multinationals in the governments of Frnando Henrique Cardoso and Luiz Iinácio Lula da Silva La selectividad espacial de las multinacionales brasileñas en los gobiernos de Fernando Henrique Cardoso y Luiz Inacio Lula da Silva La sélectivité spatiale des multinationales brésiliennes dans les gouvernements de Fernando Henrique Cardoso et Luiz Inácio Lula da Silva

Luís Alberto Miranda Goveia e Elzira Lucia de Oliveira

\section{Introdução}

1 Na dinâmica globalizadora, em que cada vez mais empresas multinacionais ampliam seu poder econômico e político, o Brasil, por meio de suas empresas e das ações de política externa e Bancos de fomento, aparece como sujeito no mundo globalizado na primeira década deste século.

2 Este trabalho analisa a seletividade espacial das empresas brasileiras de forma geral e em particular nos governos dos ex-presidentes Fernando Henrique Cardoso (FHC) (1995-2002) e Luis Inácio Lula da Silva (Lula) (2003-2010). São identificadas as empresas brasileiras que se internacionalizaram desde o final da década de 1950, bem como as empresas que se internacionalizaram pela primeira vez durante cada um dos governos analisados. Adicionalmente analisam-se as principais empresas brasileiras internacionalizadas que ampliaram a sua presença internacional nos períodos em análise. Além da pesquisa bibliográfica, este trabalho utilizou pesquisa documental e 
busca seletiva em sites de empresas multinacionais para identificar as formas de internacionalização e as suas decisões locacionais.

Os dados levantados por meio dos procedimentos metodológicos realizados foram tratados e organizados em gráficos e tabelas. Acrescenta-se ainda que foi realizada a espacialização do destinos das multinacionais por meio do Aplicativo ArcGis visando identificar o padrão espacial da localização das multinacionais brasileiras durante os governos FHC e Lula.

4 Na segunda seção apresentam-se as principais teorias sobre internacionalização de empresas e especificamente a da Escola de Uppsala; a terceira seção aborda o processo de internacionalização das empresas brasileiras; na quarta seção analisa-se a internacionalização das empresas brasileiras durante os governos de Fernando Henrique Cardoso e Luiz Inácio Lula da Silva. Finalmente, na última seção, são feitas as considerações finais do trabalho.

\section{A internacionalização de empresas}

5 A literatura sobre o internacionalização de empresas apresenta três formas básicas de internacionalização: a exportação de mercadorias, o licenciamento de tecnologia e o investimento externo, que pode ser direto (IED) ou de portfólio. Gonçalves (1998) apresenta a diferença entre o Investimento de portfólio e o IED:

O investimento externo direto envolve a compra de cotas ou ações em empresas no exterior com o propósito de exercer o controle sobre a empresa receptora do investimento. (...) O investimento externo de portfólio corresponde aos fluxos de capitais que não são orientados para o controle operacional da empresa receptora do capital externo (GONÇALVES, 1998, p.123).

6 Essas duas formas de investimento também se diferenciam pelo percentual de participação do investidor estrangeiro na empresa. Quando a participação se limita a até $10 \%$ do capital, ela é considerada como investimento de portfólio, quando ultrapassa $10 \%$, permitindo que o investidor participe do processo de gestão da empresa, caracteriza-se como Investimento Externo Direto (IED). Em suas contribuições sobre o IED, Gonçalves afirma ainda que este pode ser considerado como "o deslocamento da empresa de seu país de origem para atuar também no exterior" (GONÇALVES, 2005, p.108).

7 Atualmente não há uma teoria geral que explique o processo de internacionalização de empresas, contudo coexistem diversas teorias que buscam explicar a internacionalização das empresas, visando responder questões como: "quando", "onde", "como" e "por que" se internacionalizar.

Dentre as teorias da internacionalização de empresas, destacam-se a Escola de Uppsala, de abordagem comportamental, que se baseia nas ideias de pesquisadores da Universidade de Uppsala na Suécia durante a década de 1970. Segundo esses pesquisadores, a "internacionalização é um processo no qual as firmas aumentam gradualmente seu envolvimento internacional" (Johanson e Vahlne, 1977, apud SANTOS, 2013, p.31) se caracterizando como um processo seqüencial. Para esses autores, a internacionalização parte de fenômenos mais básicos para processos mais complexos, como por exemplo, da exportação de mercadorias e implantação de subsidiária até a instalação de uma planta de produção no país receptor do 
investimento. Esse modelo assume a premissa de que o conhecimento internacional, adquirido por meio da experiência, é fundamental no processo de internacionalização.

Outra contribuição dessa teoria é o conceito de distância psíquica que a Escola de Uppsala definiu como "a soma dos fatores que interferem no fluxo de informação entre países" (HILAL; HEMAIS, 2003, p.115). A incerteza com o resultado de uma ação da empresa aumenta com a distância psíquica entre o país de origem e o país receptor do investimento. Dentre os fatores que afetam a distância psíquica estão o nível de desenvolvimento do país, conteúdo educacional, idioma, cultura, sistema político e a forma de fazer negócios.

10 A distância psíquica permite compreender por que as empresas suecas, objeto de estudo no modelo de Uppsala, começaram o seu processo de internacionalização em mercados que apresentavam alguma proximidade geográfica ou psicológica, a exemplo de cultura similar, para gradualmente se inserir em mercados com uma distância psíquica maior. o fator localização está compreendido nessa teoria, já que as empresas atuariam, de maneira gradual, primeiro em países próximos geograficamente ou com culturas similares (distância psíquica) para depois partirem para outros mercados.

11 A escolha exclusiva pela abordagem da Escola de Uppsala, que busca explicar a internacionalização de empresas, primeiramente, para países que apresentam menor distância psíquica ocorre por estar ser a teoria que melhor se relaciona com a expansão internacional das empresas brasileiras, conforme se verificará nas próximas seções.

\section{A internacionalização das empresas brasileiras}

12 O relatório da Fundação Dom Cabral (FDC) 2011 construiu um indicador de internacionalização e apresenta o ranking das maiores multinacionais brasileiras no ano de $2010^{1}$ (tabela 1), segundo o indicador de internacionalização construído ${ }^{2}$.

13 A JBS-Friboi foi classificada no ano de 2010 como a empresa mais internacionalizada do Brasil, seguida pelas Stefanini IT Solutions, Gerdau, Ibope, Marfrig, respectivamente (FDC, 2011).

14 O mesmo relatório apresenta as empresas que têm maior número de unidades no exterior, sejam escritórios comerciais, centros de distribuição, unidades produtivas, centros de montagem ou prestação de serviços. Nesse indicador, as empresas que lideraram o ranking com maior presença física no exterior foram: Vale, Andrade Gutierrez, Votorantim e Stefanini IT Solutions (FDC, 2011). 
Tabela 1

Ranking das empresas brasileiras mais internacionalizadas em 2010

\begin{tabular}{|c|c|c|c|}
\hline Posiçäo & Empresa & Setor principal & $\begin{array}{c}\text { Índice de } \\
\text { transnacionalidade }\end{array}$ \\
\hline 1 & JBS-Friboi & Alimentos & 0,596 \\
\hline 2 & Stefanini IT Solutions & Tecnologia da Informação & 0,469 \\
\hline 3 & Gerdau & Siderurgia e Metalurgia & 0,462 \\
\hline 4 & Ibope & Pesquisa de Mercado e Opinião & 0,423 \\
\hline 5 & Marfrig & Alimentos & 0,380 \\
\hline 6 & Metalfrio & Refrigeradores & 0,337 \\
\hline 7 & Odebrecht & Construção & 0,327 \\
\hline 8 & Suzano & Celulose e Papel & 0,315 \\
\hline 9 & Sabó & Autopeças & 0,311 \\
\hline 10 & Vale & Mineração & 0,292 \\
\hline 11 & Magnesita & Produtos Refratários & 0,288 \\
\hline 12 & Tigre & Material de Construção & 0,263 \\
\hline 13 & Lupatech & Equipamentos e Peças & 0,238 \\
\hline 14 & Artecola & Produtos Quimicos & 0,220 \\
\hline 15 & Votorantim & Cimento, Metalurgia, Celulose e Papel & 0,205 \\
\hline 16 & Weg & Máquinas e Materiais Elétricos & 0,199 \\
\hline 17 & Brasil Foods & Alimentos & 0,195 \\
\hline 18 & Embraer & Aeronáutico & 0,187 \\
\hline 19 & Ci\&T Software & Tecnologia da Informação & 0,158 \\
\hline 20 & Marcopolo & Veiculos Automotores e Carrocerias & 0,158 \\
\hline 21 & Camargo Corrêa & Construção, Cimentos, Têxteis e Calçados & 0,157 \\
\hline 22 & Tam & Transporte Aéreo & 0,131 \\
\hline 23 & Agrale & Veiculos Automotores e Implementos & 0,129 \\
\hline 24 & América Latina & Logistica & 0,097 \\
\hline 25 & Natura & Cosméticos e Higiene Pessoal & 0,097 \\
\hline 26 & Azalëia & Calçados & 0,093 \\
\hline 27 & Petrobras & Petróleo e Gás Natural & 0,083 \\
\hline 28 & BRQ IT Services & Tecnologia da Informação & 0,080 \\
\hline 29 & Cia Providência & Higiênicos e Descartáveis & 0,061 \\
\hline 30 & Alusa & Energia Elètrica & 0,053 \\
\hline 31 & Andrade Gutierrez & Construção & 0,047 \\
\hline 32 & Minerva & Alimentos & 0,044 \\
\hline 33 & Bematech & Tecnologia da Informação & 0,041 \\
\hline 34 & Ultrapar & Produtos Quimicos e Distribuição de Combustiveis & 0,030 \\
\hline 35 & DHB & Autopeça & 0,030 \\
\hline
\end{tabular}

FONTE: FDC, 2011.

15 Com o objetivo de identificar a espacialidade dos primeiros investimentos de empresas brasileiras no exterior, o quadro 1 apresenta informações do destino e o ano em que foram realizados investimentos no exterior. Os dados identificam 96 empresas que realizaram investimento por meio de IED desde o final da década de 1950 até o ano de 2010.

16 Verifica-se que mais da metade, (54\%) das empresas elegeu a América do Sul como destino inicial de suas atividades internacionais, enquanto que a América do Norte (exceto México) e a Europa responderam por $18 \%$ e 16\%, respectivamente. Analisados individualmente, a Argentina e os EUA foram os países mais selecionados pelas empresas brasileiras para iniciar atividades em território estrangeiro. A Argentina foi o território selecionado por 22 empresas, ao passo que Os Estados Unidos da América foi o destino de 16 empresas, seguidos pelo Chile, onde oito empresas iniciaram suas operações internacionais. Dentre essas empresas cita-se a Ambev, Stefanini It Solutions, JBS Friboi e Marfrig na Argentina e Vale, Embraer, WEG e Votorantim nos EUA.

17 Segundo Sposito e Santos, diversos fatores contribuíram para o início das atividades internacionais de empresas brasileiras, entre as quais destacam-se: capacidade tecnológica e administrativa adquirida durante a consolidação da industrialização e da acumulação do capital do país, oferta de produtos e serviços de alto padrão, adaptação de tecnologias de produtos e processos adequadas às condições dos países subdesenvolvidos, utilização de fatores de produção mais baratos do Brasil, benefícios da integração latino-americana e das isenções fiscais, aquisição de marcas e redes de distribuição, obtenção de tecnologia estratégica mediante uso de tecnologia de vanguarda, atendimento a mercados externos por intermédio de subsidiárias, 
desaceleração do mercado doméstico, prioridades governamentais, busca de mercados, ativos estratégicos e proximidade do cliente (SPOSITO; SANTOS, 2012). Os fatores que contribuíram para a expansão internacional de empresas brasileiras devem ser entendidas no contexto de vantagens específicas das empresas ou setores econômicos e o cenário macroeconômico que possibilitou esses investimentos em cada período.

Quadro 2

Principais Empresas multinacionais Brasileiras com IED, segundo ano de internacionalização, país e região de localização

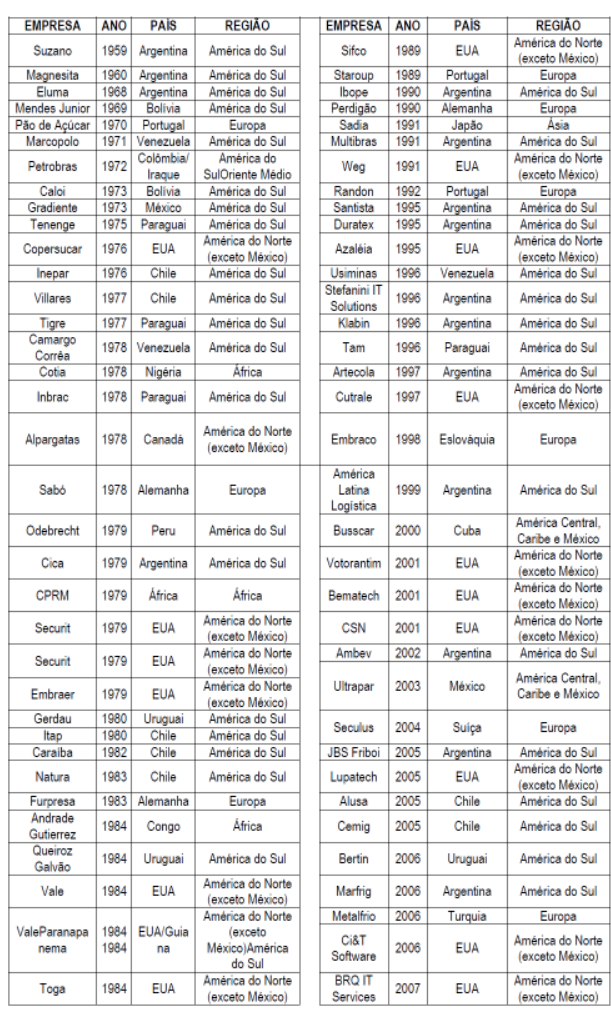

Fonte:Fundação dom Cabral (2011); Sposito, Santos (2012a); Informações disponíveis na home Page das empresas. Organizado pelo autor. 
Quadro 2 - Continuação

Principais Empresas multinacionais Brasileiras com IED, segundo ano de internacionalização, país e região de localização

\begin{tabular}{|c|c|c|c|c|c|c|c|}
\hline Bardella & 1985 & EUA & $\begin{array}{l}\text { América do Norte } \\
\text { (exceto México) }\end{array}$ & Unigel & 2006 & México & $\begin{array}{l}\text { América Central, } \\
\text { Caribe e México }\end{array}$ \\
\hline Globo & 1985 & Ittália & Europa & \multirow{2}{*}{ Tegma } & \multirow{2}{*}{2007} & \multirow{2}{*}{ Venezuela } & \multirow{2}{*}{ América do Sul } \\
\hline Metal Leve & 1985 & Inglaterra & Europa & & & & \\
\hline \multirow[b]{2}{*}{ Cofap } & \multirow[b]{2}{*}{ s.d. } & \multirow[b]{2}{*}{ Alemanha } & \multirow[b]{2}{*}{ Europa } & Camil & 2007 & Uruguai & América do Sul \\
\hline & & & & $\begin{array}{l}\text { Brasil } \\
\text { Foods }\end{array}$ & 2008 & Holanda & Europa \\
\hline \multirow{2}{*}{ Labra } & \multirow{2}{*}{1985} & \multirow{2}{*}{ Portugal } & \multirow{2}{*}{ Europa } & Agrale & 2008 & Argentina & América do Sul \\
\hline & & & & Minerva & 2008 & Paraguai & América do Sul \\
\hline Nansen & 1985 & Colômbia & América do Sul & $\mathrm{Oi}$ & 2008 & Moçambique & África \\
\hline Grendene & 1985 & Argentina & América do Sul & Bom Retiro & 2008 & Argentina & América do Sul \\
\hline Hering & 1985 & Argentina & América do Sul & $\begin{array}{c}\text { Independê } \\
\text { ncia }\end{array}$ & 2008 & Paraguai & Améric \\
\hline Vachi & 1985 & Inglaterra & Europa & Schulz & 2008 & China & Ásia \\
\hline \multirow{2}{*}{ Sharp } & \multirow{2}{*}{1985} & \multirow{2}{*}{ EUA } & \multirow{2}{*}{$\begin{array}{l}\text { América do Norte } \\
\text { (exceto México) }\end{array}$} & Eurofarma & 2009 & Argentina & América do Sul \\
\hline & & & & Vulcabras & 2009 & Argentina & América do Sul \\
\hline Cacique & 1987 & China & Ásia & Braskem & 2009 & México & $\begin{array}{l}\text { América Central, } \\
\text { Caribe e México }\end{array}$ \\
\hline Brahma & 1987 & Argentina & América do Sul & lochep- & 2010 & EUA & América do Norte \\
\hline Incasa & 1988 & Chile & América do Sul & Maxion & 2010 & $E \cup A$ & (exceto México) \\
\hline
\end{tabular}

Fonte:Fundação dom Cabral (2011); Sposito, Santos (2012a); Informações disponíveis na home Page das empresas. Organizado pelo autor.

Constata-se, a partir dos dados apresentados no quadro 2, que a internacionalização de empresas brasileiras por meio de IED não é um fenômeno novo, constam operações da Suzano em 1959 e Magnesita em 1960.

\section{A internacionalização de empresas no período FHC e Lula}

19 Do total de empresas brasileiras que realizaram algum investimento externo direto desde 1959 até 2010 , aproximadamente $43 \%$ se internacionalizaram pela primeira vez durante os governos de FHC (1995-2002) e Lula (2003-2010).

20 A Linha do Tempo apresentada na figura 1 permite comparar o número de empresas que se internacionalizaram durante os governos dos dois ex-presidentes. Verifica-se que durante os dois mandatos do presidente Fernando Henrique Cardoso apenas 16 empresas brasileiras se internacionalizaram. Em contraposição, durante os anos do governo Luís Inácio Lula da Silva, 25 empresas se internacionalizaram por meio de IED. 
Figura 1

Linha do Tempo: Primeira Internacionalização via ied de empresas brasileiras no período FHC (1995-2002) e Lula (2003-2010).

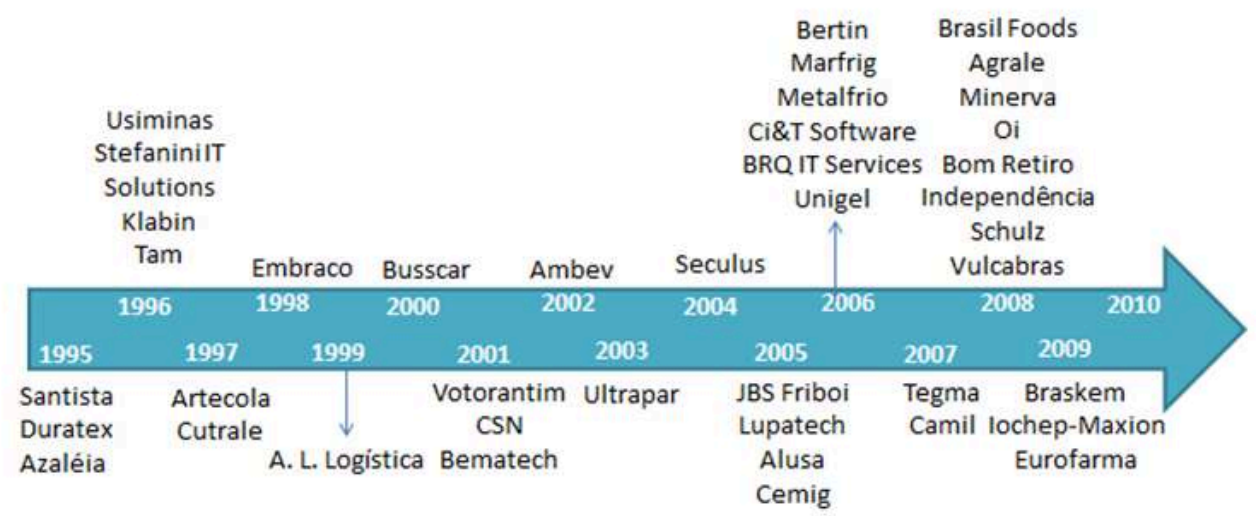

Fonte:Fundação dom Cabral (2011); Sposito, Santos (2012); Informações disponíveis na home Page das empresas. Organizado pelo autor. período das gestões do ex-presidente Fernando Henrique Cardoso. Já nos governos do ex-presidente Luís Inácio Lula da Silva, os anos de 2006 e 2008 foram aqueles em que maior número de empresas iniciaram suas atividades no exterior.

figura 2 apresenta a espacialização dos destinos de IED de empresas brasileiras que se internacionalizaram pela primeira vez, durante o governo FHC e Lula. Verifica-se que no período FHC houve uma concentração regional, principalmente na América do Sul, como destino inicial de internacionalização. Das 16 empresas que se internacionalizaram nesse período, nove iniciaram suas atividades na região, enquanto cinco investiram na América do Norte (exceto México), e uma se direcionou para a Europa e outra para a América Central e México. A Argentina foi o país selecionado por sete empresas, já os Estados Unidos foi eleito por três empresas. Paraguai e a Venezuela receberam uma empresa cada um.

No período que compreende o governo Lula (2003-2010) verifica-se diversificação dos destinos das operações internacionais de empresas brasileiras via IED. Em que pese a América do Sul permanecer como o principal destino, sendo o lócus privilegiado de 15 das 25 empresas que iniciaram suas atividades internacionais, outras regiões aparecem como destino dos primeiros investimentos internacionais de empresas brasileiras: América do Norte (exceto México) recebeu quatro empresas, América Central e México receberam três, o continente Europeu recebeu investimentos de três empresas, a África e Ásia foram destino de uma empresa cada.

Apesar dessa diversificação espacial, muitas empresas ainda continuaram investindo, primeiramente nos países vizinhos. Durante o governo Lula, a Argentina também foi destino principal das empresas brasileiras para iniciar as operações internacionais, recebendo investimentos de seis empresas, já EUA foi de quatro empresas e o México aparece na sequência com três empresas.

Cumpre ressaltar que duas das quatro empresas elegeram os EUA como primeiro destino das operações internacionais são do setor de tecnologia da informação (Ci\&T Software e BRQ IT Services). A empresa JBS-Friboi, que iniciou seu processo de 
internacionalização no período do governo Lula, recebeu financiamento do BNDES para iniciar sua inserção internacional por meio de IED.

Além da Argentina, outros países sul-americanos também foram o primeiro destino de internacionalização de empresas brasileiras, como, por exemplo, o Chile, Uruguai e Paraguai que receberam, cada um, duas empresas.

Dados apresentados em Sposito e Santos (2012) e na home page das empresas multinacionais brasileiras permitem afirmar que 10 das 16 empresas que se internacionalizaram no período 1995-2002 iniciaram as atividades internacionais por meio de aquisição de outras empresas. Entre essas, cita-se a CSN, Ambev e Tigre. A Klabin e Embraco instalaram plantas industriais nos países de destino. A Usiminas se internacionalizou por meio de participação acionária, a Multibras por meio de uma joint venture e a Azaléia e Bematech instalaram filiais de vendas.

Figura 2

Espacialização do Destino das empresas brasileiras durante os governos FHC e Lula



Fonte: Elaborado pelo autor. com base em SPOSITO; SANTOS, (2012); Sites oficiais das empresas.

No governo Lula, das 25 empresas que iniciaram sua internacionalização, 15 o fizeram por meio da aquisição de outras empresas, entre essas estão a JBS-Friboi, Marfrig, Metalfrio e Eurofarma. A Braskem, Schulz, Tegma e Seculus optaram por se internacionalizar por intermédio de joint ventures. A Agrale foi a única empresa, presente na pesquisa, cuja internacionalização foi por meio da implantação de uma planta industrial no país destino. As empresas do setor de tecnologia Brq IT Services e Ci\&T Softwares abriram filiais de vendas no início de sua internacionalização, a Cemig e Alusa se inseriram no mercado internacional exportando serviços (energia e infraestrutura, respectivamente).

Algumas empresas que se internacionalizaram por meio de IED, durante os governos de FHC e Lula, expandiram seus investimentos nesse período para outros países, além disso, empresas que já haviam se internacionalizado anteriormente, também expandiram suas operações internacionais no interregno destes dois governantes.

No quadro 3 apresenta-se a expansão internacional de empresas brasileiras durante o governo FHC e, por meio dos dados, é possível afirmar que Petrobrás (expandiu para oito países), Odebrecht (sete países), Andrade Gutierrez (seis países) e Stefanini IT Solutions (cinco países) foram as que mais se expandiram. Algumas dessas empresas 
apresentaram mais de uma operação em um mesmo país. A Gerdau e Tigre, por exemplo, apesar de terem se expandido para três países, realizaram sete e seis operações de expansões internacionais, respectivamente.

Quadro3

Empresas que se internacionalizaram durante o governo $\mathrm{FHC}$, por anos e país de destino

\begin{tabular}{|c|c|c|c|c|c|}
\hline Empresa & Ano & Destino & Empresa & Ano & Destino \\
\hline Andrade Gutierrez & 1995 & Portugal & Odebrecht & 1997 & Colômbia \\
\hline Andrade Gutierrez & 1995 & Irã & Odebrecht & 2002 & Bolivia \\
\hline Andrade Gutierrez & 1995 & EUA & Odebrecht & 2002 & Djibuti \\
\hline Andrade Gutierrez & 1996 & Camarões & Odebrecht & 2002 & República Dominicana \\
\hline Andrade Gutierrez & 1996 & Peru & Petrobras & 1995 & Bolivia \\
\hline Andrade Gutierrez & 2002 & República Dominicana & Petrobras & 1996 & Equador \\
\hline Andrade Gutierrez & 2002 & Peru & Petrobras & 1997 & Bolivia \\
\hline Artecola & 1997 & Argentina & Petrobras & 1998 & Colômbia \\
\hline Artecola & 2000 & Chile & Petrobras & 1998 & Nigèria \\
\hline Azaléia & 2000 & Colômbia & Petrobras & 1998 & Austrália \\
\hline Azaléia & 2000 & Peru & Petrobras & 1999 & Bolivia \\
\hline Azaléia & 2000 & Chile & Petrobras & 1999 & Argentina \\
\hline Azaléia & 2001 & Rep Tcheca & Petrobras & 2000 & Japão \\
\hline Azaléia & 2002 & México & Petrobras & 2001 & Argentina \\
\hline Busscar & 1998 & México & Petrobras & 2002 & Argentina \\
\hline Busscar & 2001 & Noruega & Petrobras & 2002 & Venezuela \\
\hline Busscar & 2002 & Colômbia & Petrobras & 2002 & Argentina \\
\hline Camargo Corrêa & 1995 & Argentina & Randon & 1998 & Argentina \\
\hline Camargo Corrêa & 1996 & Colômbia & Sabó & 1997 & Reino Unido \\
\hline Camargo Corrêa & 1997 & Peru & Sabó & 1997 & Itália \\
\hline Camargo Corrêa & 1999 & Chile & Sabó & 1997 & Hungria \\
\hline Coteminas & 2001 & Argentina & Santista & 1995 & Argentina \\
\hline Duratex & 1995 & Argentina & Santista & 1999 & Chile \\
\hline Gerdau & 1995 & Canadá & Stefanini IT Solutions & 2000 & Chile \\
\hline Gerdau & 1997 & Argentina & Stefanini IT Solutions & 2000 & México \\
\hline Gerdau & 1998 & Argentina & Stefanini IT Solutions & 2001 & Colômbia \\
\hline Gerdau & 1999 & EUA & Stefanini IT Solutions & 2001 & EUA \\
\hline Gerdau & 2002 & EUA & Stefanini IT Solutions & 2001 & Peru \\
\hline Gerdau & 2002 & EUA & Suzano & 2001 & Portugal \\
\hline Gerdau & 2002 & EUA & Tigre & 1997 & Chile \\
\hline Marcopolo & 1998 & Argentina & Tigre & 1998 & Argentina \\
\hline Marcopolo & 1999 & México & Tigre & 1999 & Argentina \\
\hline Marcopolo & 1999 & México & Tigre & 1999 & Chile \\
\hline Marcopolo & 2001 & Colômbia & Tigre & 2000 & Bolivia \\
\hline Marcopolo & 2001 & África do Sul & Tigre & 2000 & Bolivia \\
\hline Marcopolo & 2001 & Colômbia & Usiminas & 1996 & Venezuela \\
\hline Marcopolo & 2001 & África do Sul & Vale & 2002 & Peru \\
\hline Multibras & 1995 & Argentina & Weg & 2000 & Argentina \\
\hline Odebrecht & 1995 & Moçambique & Weg & 2000 & Argentina \\
\hline Odebrecht & 1996 & Botsuana & Weg & 2002 & México \\
\hline Odebrecht & 1997 & Colômbia & Weg & 2002 & Portugal \\
\hline \multirow{2}{*}{\multicolumn{3}{|c|}{ Aifica do Sul }} & Vale & 2002 & Peru \\
\hline & & & 84 operacões & & paises \\
\hline
\end{tabular}

Fonte:Fundação dom Cabral (2011); Sposito, Santos (2012); Informações disponíveis na home Page das empresas. Organizado pelo autor.

31 A figura 3 mostra a distribuição espacial dos investimentos realizados pelas multinacionais brasileiras durante o governo de FHC. No período correspondente (1995-2002) foram realizadas 84 operações de expansão internacional direcionadas a 26 países diferentes, enquanto que durante o governo Lula (2003-2010) foram realizadas 214 operações de internacionalização destinadas a 55 países distintos.

Durante o governo FHC, a Argentina recebeu 12 diferentes empresas multinacionais (EM's) brasileiras, já internacionalizadas, se consolidando como o principal destino das multinacionais do Brasil, com destaque para a Gerdau, Petrobras, Tigre e Weg que realizaram mais de um tipo de operação no país. Destacam-se ainda a Colômbia com a atuação de sete EM's brasileiras, entre elas a Marcopolo e Odebrecht.

33 No contexto geral, as empresas que mais expandiram operações no exterior foram a Petrobras com 12 operações em oito países diferentes, a Odebrecht com oito operações em sete países e a Andrade Gutierrez, Marcopolo e Gerdau com sete operações cada. 
Figura 3

Distribuição espacial da expansão das empresas multinacionais (em's) brasileiras durante o governo FHC - 1995-2002

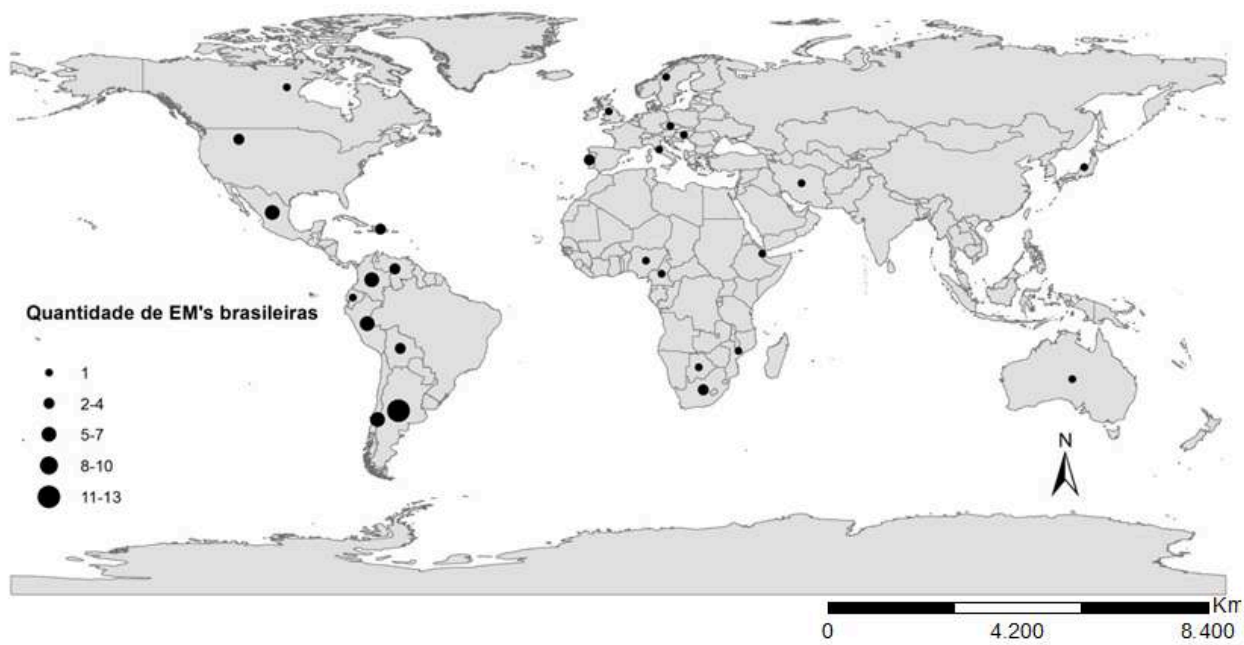

Fonte: Elaborado pelo autor, com base em SPOSITO; SANTOS, (2012); Sites oficiais das empresas.

As operações das EM's brasileiras no período incluem tanto a instalação de plantas industriais, escritórios comerciais, exportação de serviços, quanto operações de fusões e aquisições de empresas locais (SPOSITO; SANTOS, 2012).

O quadro 4 apresenta os destinos de IED por empresa durante os oito anos de governo Lula, verifica-se que as principais empresas que ampliaram suas operações internacionais, expandindo o IED pelo mundo foram: Petrobrás (13 países), Vale (10 países), Marfrig e Gerdau (nove países) e Odebrecht e Votorantim (sete países). 
Quadro 4

Empresas que se internacionalizaram durante o governo Lula, por anos e país de destino

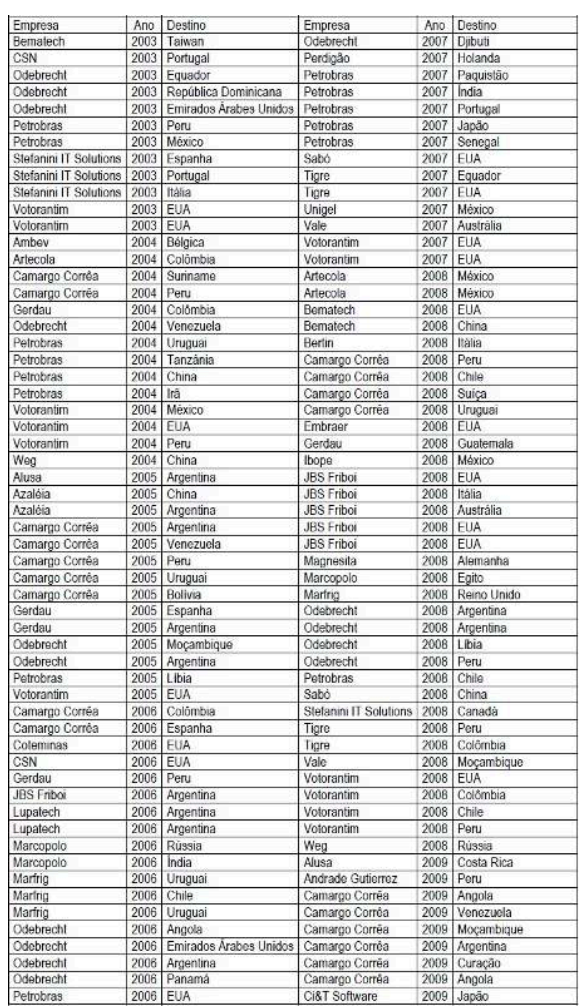

Fonte:Fundação dom Cabral (2011); Sposito, Santos (2012); Informações disponíveis na home Page das empresas. Organizado pelo autor. 
Quadro 4 - Continuação

Empresas que se internacionalizaram durante o governo Lula, por anos e país de destino



Fonte:Fundação dom Cabral (2011); Sposito, Santos (2012); Informações disponíveis na home Page das empresas. Organizado pelo autor.

Conforme se observa na figura 4, aproximadamente $60 \%$ do total de empresas se direcionaram para a América do Sul em suas operações de expansão, enquanto que a Europa foi o destino de $11 \%$ das empresas, a África, a América Central e México receberam oito operações de EM's brasileiras, que representam $10 \%$ dos investimentos para os respectivos destinos. Dessa forma, a América do Sul foi a região que mais recebeu operações internacionais de EM's brasileiras no período FHC, da mesma forma que foi o destino preferencial da primeira operação internacional.

A figura 4 permite ainda afirmar que as empresas brasileiras, nos anos do governo Lula, mantiveram a expansão internacional preferencialmente para América do Sul, entretanto, observa-se certa diversificação espacial dos investimentos internacionais com presença mais marcante para outras regiões do mundo. Se comparado com o período do presidente FHC, apesar do aumento em números absolutos, a América do Sul diminuiu a sua participação no período Lula, enquanto todas as outras regiões aumentaram participação, principalmente a América Central e México.

A diminuição da participação da América do Sul como destino preferencial das operações internacionais de multinacionais brasileiras pode revelar o desenvolvimento internacional dessas empresas, bem como a apropriação de novas vantagens de propriedade ou fatores locacionais mais atrativos em outras regiões do planeta. 
Figura 4

Expansão das multinacionais brasileiras no período FHC e Lula

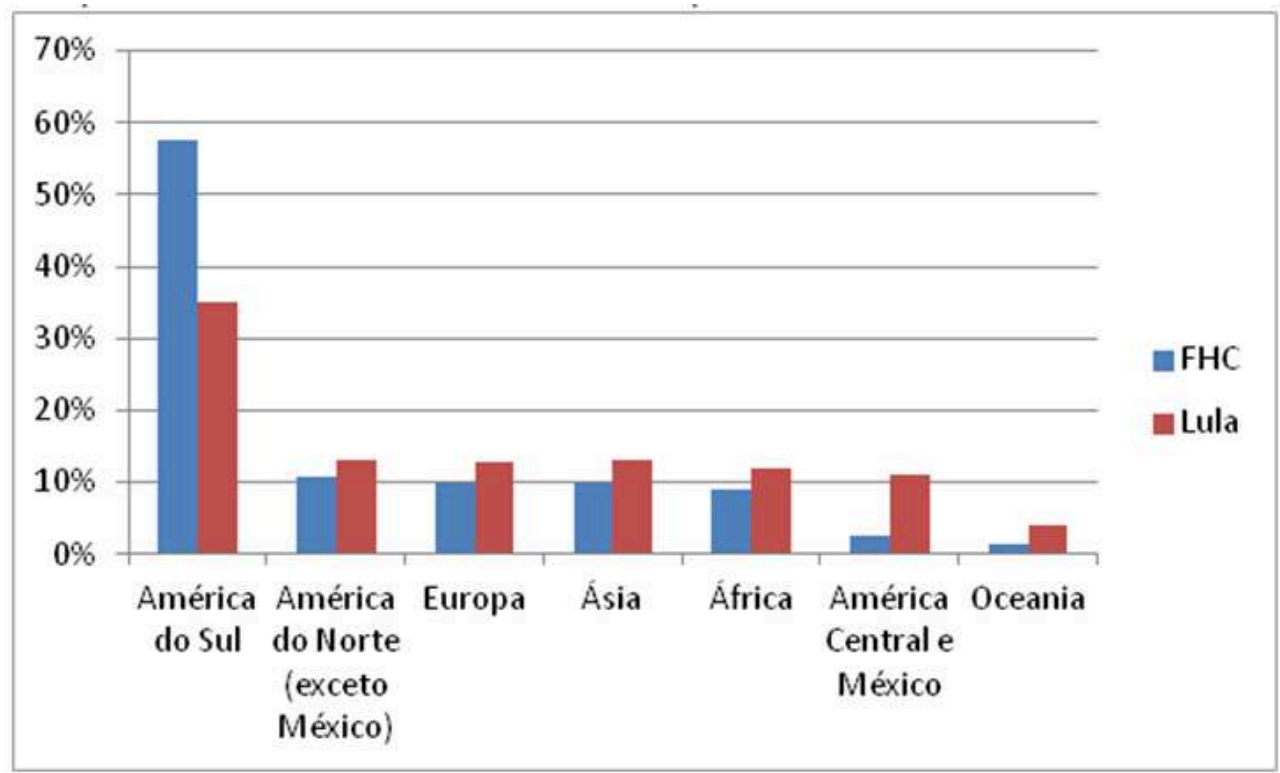

Fonte: Elaborado pelo autor, com base em SPOSITO; SANTOS, (2012); Sites oficiais das empresas.

39 A figura 5 permite visualizar a ampliação e diversificação dos países que receberam IED e exportação de serviços de engenharia brasileiros durante o governo Lula. Os dados confirmam as teorias de que o Brasil tem ampliado seus parceiros e investido em países em desenvolvimento devido as características culturais e do próprio nível de desenvolvimento desses países. Mais de $70 \%$ dos países que receberam investimentos brasileiros foram países emergentes ou em desenvolvimento. Contudo regiões desenvolvidas como Europa, EUA, Canadá, Japão e Austrália também têm recebido maior aporte de IED brasileiro, principalmente por meio da aquisição de empresas locais, por empresas brasileiras, já que esses são considerados mercados importantes no contexto global.

Individualmente, os Estados Unidos da América foi o país que mais recebeu novos investimentos de empresas brasileiras no período 2003-2010, totalizando 28 operações realizadas por 15 diferentes EM's. Entre as principais empresas brasileiras no país por número de operações no período, se destacam a Votorantim (sete), JBS Friboi (seis) e Gerdau (três). A Argentina que durante o governo FHC foi o principal destino das EM's brasileiras, aparece como o segundo principal destino no período que compreende o governo Lula, com 24 operações internacionais realizadas por 10 empresas, das quais se destacam a JBS-Friboi, Odebrecht e Lupatech. O país que aparece como o terceiro principal destino das operações de internacionalização de empresas brasileiras foi o Peru, que recebeu oito multinacionais em 15 diferentes operações de investimentos, já a China recebeu 10 diferentes empresas brasileiras em 10 operações internacionais.

41 Na Europa e África os países que mais receberam investimentos de empresas brasileiras foram Portugal, Angola e Moçambique, três países que apresentam certa proximidade cultural com o Brasil, proporcionado pelo fator linguístico e laços históricos. Portugal recebeu investimentos de cinco empresas brasileiras enquanto Moçambique recebeu quatro e Angola três. 
No período 2003-2010 que compreende os dois mandatos do presidente Lula, algumas empresas se destacaram nos seus projetos de expansão internacional. Entre elas estão as construtoras Camargo Corrêa com 28 operações internacionais (16 países) e a Odebrecht com 23 operações internacionais (14 países). Outras empresas também alargaram seus investimentos internacionais, como, por exemplo, a Marfrig com 19 operações distribuídas em 11 países, a Votorantim também com 19 operações, mas apenas em 9 países e a JBS-Friboi com 10 operações (10 países).

Figura 5

Distribuição espacial da expansão das empresas multinacionais (em's) brasileiras durante o governo Lula (2003-2010)

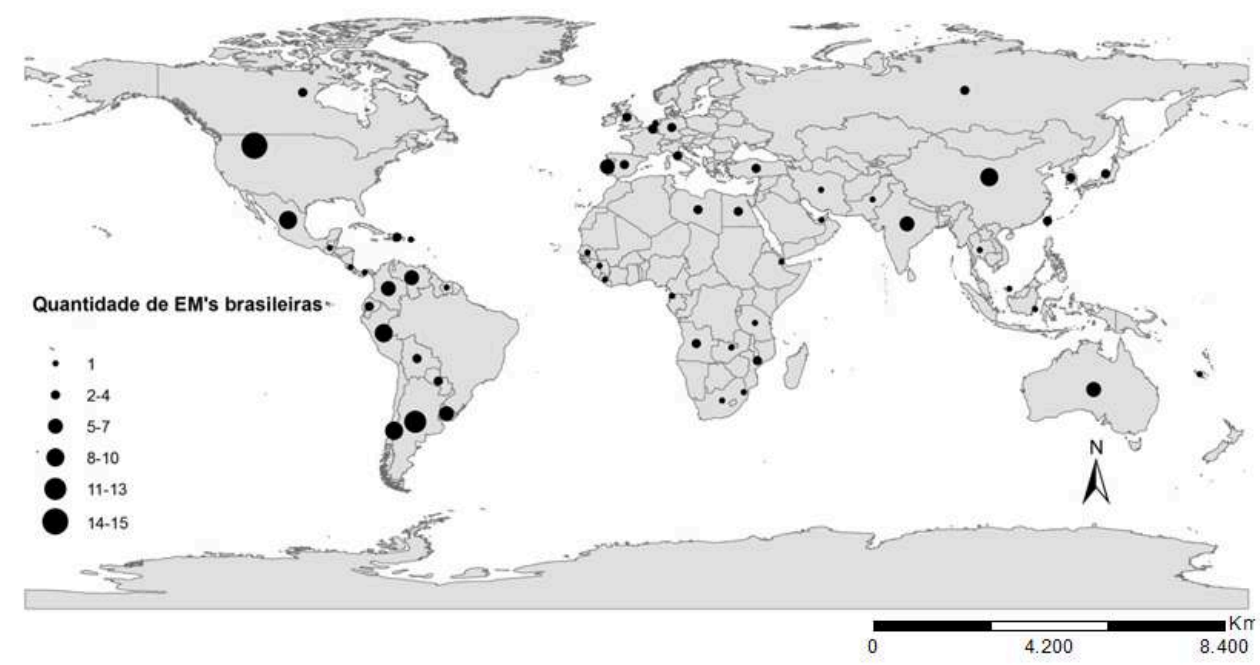

Fonte: Elaborado pelo autor, com base em SPOSITO; SANTOS, (2012); Sites oficiais das empresas.

Algumas empresas que apenas exportavam para determinados países, passaram a ter centros de distribuição ou mesmo unidades produtivas, como por exemplo, a Marcopolo, Tigre e Randon, sugerindo aderência à teoria da Escola de Uppsala de que as empresas se internacionalizam de maneira gradativa iniciando pela exportação de produtos e serviços, para posteriormente, realizar algum tipo de operação de IED. Contudo o grande número de aquisições em projetos de internacionalização evidenciam que algumas empresas não se internacionalizam de forma gradativa e, desta forma, contribuem para a centralização do capital na medida em que buscam mercados e marcas já consolidados nos países de destino. Relacionando os dados sobre as primeiras regiões de destino da internacionalização de empresas brasileiras nos períodos FHC e Lula com a teoria da Escola de Uppsala, pode-se inferir que durante a gestão dos dois presidentes, a quantidade de empresas que se internacionalizou para a América do Sul foi semelhante representando $56 \%$ e $60 \%$, respectivamente. Contudo o número de empresas que se internacionalizou para outras regiões com maior distância psíquica é considerável, concluindo-se que a teoria da Escola de Uppsala não se aplica ao processo de internacionalização da totalidade de empresas, devendo-se analisar outros fatores que expliquem a internacionalização.

Os dados apresentados confirmam a expansão das multinacionais brasileiras nos últimos anos, especialmente durante o governo Lula, período no qual houve incentivo à internacionalização de empresas brasileiras por meio de financiamentos do Banco Nacional de Desenvolvimento Econômico e Social (BNDES) e pelas diretrizes da política 
externa que procurou diversificar os parceiros comerciais do Brasil no globo. A América do Sul permanece como o principal espaço de reprodução do capital brasileiro, tanto no estágio inicial quanto na expansão da internacionalização. Contudo novos espaços como a África surgem no cenário dos investimentos das grandes construtoras brasileiras e regiões desenvolvidas do mundo recebem cada vez mais IED brasileiro, principalmente pela aquisição de empresas estrangeiras pelas empresas brasileiras.

\section{Considerações finais}

As empresas brasileiras têm ampliado a sua presença internacional com a instalação de novos projetos, aquisição e fusão de empresas no país destino, joint ventures, centros de distribuição de equipamentos e produtos, escritórios comerciais, prestação de serviços, consistindo em um fenômeno que não se restringe aos países desenvolvidos.

Considerando o recorte temporal do trabalho percebe-se que mais da metade das empresas brasileiras que iniciaram seus projetos de internacionalização no governo FHC e Lula privilegiaram a América do Sul. Essa escolha locacional se aproxima dos pressupostos da teoria de internacionalização da Escola de Uppsala de que as empresas tendem a se internacionalizar, inicialmente, em espaços que apresentam similiaridade cultural, mesmo nível de desenvolvimento e menor distância geográfica, que é denominado de distância psíquica. A opção pela menor distância psiquíca visa diminuir os riscos da internacionalização, embora, alguns críticos afirmem que com a globalização essa seletividade espacial privilegiando a menor distância psíquica se verifique em menor intensidade. Apesar do modelo de internacionalização da Escola de Uppsala se relacionar melhor com a análise da seletividade espacial das empresas brasileiras verificada ao longo deste trabalho, no que concerne ao movimento gradativo de internacionalização, que a referida escola afirma se iniciar com a exportação, depois licenciamento e por fim IED, os dados evidenciam que grande parte das EM's brasileiras optaram, no período em questão, por se internacionalizar por meio da aquisição de empresas, seja para aproveitar as marcas, mercados consolidados ou mais competitivos ou mesmo para incorporar tecnologias e Know-how.

Em que pese, tanto no governo de FHC quanto na gestão de Lula, a América do Sul ter sido o principal destino das empresas brasileiras, durante o governo Lula, houve redução da participação sul-americana, na medida em que todas as outras regiões aumentaram participação. Se no governo FHC foi Argentina que mais recebeu EM's brasileiras na primeira operação de internacionalização, durante o governo Lula, o principal destino foram os Estados Unidos da América, revelando mudanças na distribuição geográfica dos investimentos brasileiros.

Empresas como a Votorantim, Odebrecht, Petrobras, JBS-Friboi, Vale, Gerdau e Marfrig foram as que mais ampliaram sua presença internacional seja com capital próprio ou com financiamento do BNDES.

Mesmo não sendo um fenômeno recente, a internacionalização de empresas brasileiras nos últimos anos tem contribuído para uma nova organização dos fluxos de investimentos em escala mundial e desenhando uma nova configuração espacial da dinâmica capitalista em que países em desenvolvimento não são apenas espaços receptores de IED. 
a crise financeira que o Brasil experimenta no início da segunda década do século XXI necessita-se rever as políticas de financiamento a internacionalização de empresas via banco público na atual conjuntura econômica que tem afetado empresas domésticas que não contam com mesmo apoio oferecido pelo BNDES. Reflexões a respeito da formação de oligopólios internacionais também precisam ser consideradas, na medida que a centralização do capital pode contribuir para a concorrência imperfeita dos mercados.

\section{BIBLIOGRAFIA}

CERQUEIRA, Daniela Franco. A Integração do Brasil com os países da América do Sul

(2003-2010): o IED brasileiro, a IIRSA e a consolidação da dependência. Niteroi, 2014. 225 f. TESE (Doutorado em Economia). Programa de Pós-Graduação em Economia da Universidade Federal Fluminense. Niteroi, 2014.

FUNDAÇÃO DOM CABRAL (FDC). Ranking das transnacionais brasileiras: crescimento e gestão sustentável no exterior. Nova Lima, 2011.

GONÇALVES, Reinaldo. Economia Política Internacional: Fundamentos teóricos e as relações internacionais do Brasil. São Paulo: Campus. 2005.

GONÇALVES, Reinaldo. et al. A nova economia internacional : uma perspectiva brasileira. Rio de Janeiro: Campus, 1998. 392p.

HILAL, Adriana; HEMAIS, Carlos A. O processo de internacionalização na ótica da Escola Nórdica: evidências empíricas em empresas brasileiras. Revista de Administração Contemporânea. [S.l.] v. 7, n. 1, Jan./Mar. 2003: 109-124

SANTOS, Leandro Bruno. Estado e internacionalização das empresas multilatinas. São Paulo: Cultura Acadêmica, 2013.577p. .

SPOSITO, Eliseu; SANTOS, Leandro Bruno. 0 capitalismo industrial e as multinacionais brasileiras. São Paulo: Outras Expressões, 2012.

\section{NOTAS}

1. A Fundação Dom Cabral é uma escola de negócios que realiza anualmente o ranking das transnacionais brasileiras utilizando a metodologia da United Nations Conference on Trade and Development (UNCTAD). O Ranking FDC de 2011 realizou pesquisa com 78 empresas com algum tipo de operação internacional. Desse total, apenas 51 responderam aos questionários, dos quais 49 foram validados.

2. $O$ indicador é calculado para as empresas que atuam no exterior a partir de unidades próprias, segundo a metodologia da UNCTAD - United Nations Conference on Trade and Development, Segundo a formula:

(Ativos no exterior) / (Ativos totais) + (Receitas no exterior) / (Receitas totais) + (Funcionários no exterior) / (Funcionários totais) 


\section{RESUMOS}

O cenário econômico mundial do início do século XXI pode ser caracterizado por mudanças na organização espacial da remessa de investimentos e origem das grandes empresas que não se restringem aos países chamados desenvolvidos. O presente trabalho busca identificar as principais multinacionais brasileiras e seus critérios de seletividade espacial no período que compreende os governos dos presidentes Fernando Henrique Cardoso e Luiz Inácio Lula da Silva relacionando com a teoria de internacionalização da Escola de Uppsala.

The global economic scenario in the early 21st century is characterized by changes in spatial organization of investment shipments as well as the origin of large companies that are not restricted to developed countries. This paper seeks to identify main Brazilian multinationals and their criteria for space selection in the period concerning the governments of presidents Fernando Henrique Cardoso and Luiz Inácio Lula da Silva relating to the Uppsala internationalization model.

El escenario económico mundial del siglo XXI es caracterizado por cambios en la organización espacial del origen de las inversiones y de las grandes empresas, que no se restringen a los países desarrollados. El presente trabajo busca identificar a las principales multinacionales brasileñas y sus criterios de selección espacial en el período que comprende los gobiernos de los presidentes Fernando Henrique Cardoso y Luiz Inácio Lula da Silva, haciendo una relación con la teoría de internacionalización de la Escuela de Uppsala.

Le scénario économique mondial du début $d u 21^{\text {ème }}$ siècle peut être caractérisé par des changements dans l'organisation spatiale des envois de fonds d'investissements et par l'origine des grandes entreprises qui ne se limitent pas aux pays dits développés. Le présent travail vise à identifier les principales multinationales brésiliennes et leurs critères de sélectivité spatiale dans la période qui comprend les gouvernements des présidents Fernando Henrique Cardoso et Luiz Inácio Lula da Silva, en les mettant em rapport avec la théorie de l'internationalisation de l'école d'Uppsala.

\section{ÍNDICE}

Mots-clés: Investissement direct étranger, Multinational Enterprises.FHC, Lula.

Palavras-chave: investimento externo direto, empresas multinacionais, FHC, Lula.

Keywords: Foreign Direct Investment; Multinational Companies; FHC; Lula.

Palabras claves: Inversiones externas directas, empresas multinacionales, Fernando Henrique Cardoso, Luiz Inácio Lula da Silva.

\section{AUTORES}

\section{LUÍS ALBERTO MIRANDA GOVEIA}

Mestre em Geografia; Universidade Federal Fluminense

Email: luis_campista@yahoo.com.br

\section{ELZIRA LUCIA DE OLIVEIRA}

Doutora em Demografia; Professora Universidade Federal Fluminense 
E-mail: elziralucia@id.uff.br 